\title{
NEW DENTAL FILM HIGHLIGHTS THE NEEDS OF DEMENTIA PATIENTS
}

A thought-provoking new film aimed at dental professionals to raise awareness of the issues faced by patients with dementia when attending a dental appointment has been launched today by Health Education England (HEE).

Sir Keith Pearson, HEE Chair will launch the film during a visit to the dental team at Health Education Thames Valley who worked with Wessex Dental team on producing the film.

Sir Keith Pearson said: 'The film gives us a real insight into just how confusing attending a dentist appointment can be for someone with dementia. Figures show that 800,000 people in the UK suffer from dementia and many of these people will have experienced visiting their local dental practice.

'It will provide dental teams with valuable information on how difficult things can be for sufferers and provide some ideas on how to make arrangements to make the process smoother and easier for their patients.'

Paul Holmes, Director South, Health Education England said: 'Twenty two million adults in England saw an NHS dentist in the 24 months to June 2014, according to the Health and Social Care Information Centre (HSCIC). A significant number of these people are likely to have difficulty with short term memory loss and may be in the early stages of dementia. Awareness of these potential issues by health care staff can significantly improve patient experiences.

'I hope this film provokes debate and gets dental teams to look at what they might do differently to help improve people's experiences and would like to congratulate the Thames Valley and Wessex Dental teams for their hard work.'

The film looks at the process of attending a dental appointment through the eyes of a dementia sufferer, highlighting just how daunting the whole process can be. It will be a useful learning tool for dental teams working in general practice and will challenge them to think about how they deal with people who suffer from this condition. It highlights the crucial role played by staff, especially receptionists and dental nurses in supporting vulnerable patients.

It has been inspired by an award winning series of films called 'Barbara's Story' that was developed to highlight issues around caring for people with dementia in an acute hospital.

A copy of the film will be available on https://youtu.be/EnPUq00UA8c.

The film was made on location at surgery of Satnam Moonga. Satnam is the Thames Valley Local Dental Professional Network Chair and who generously allowed use of his surgery in Princes Risborough.
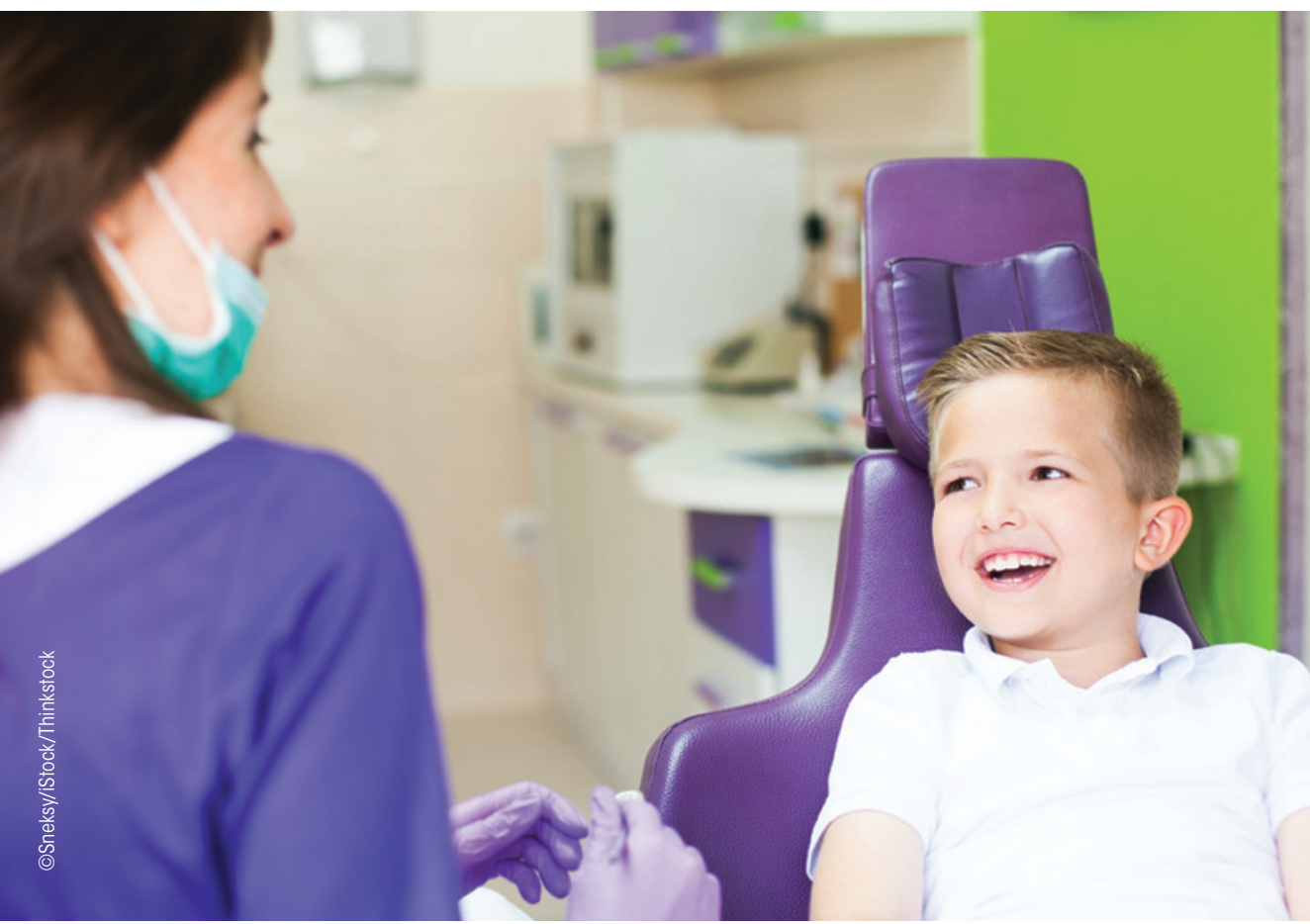

FACULTY OF DENTAL SURGERY ALARMED BY NINEFOLD VARIATION IN HOSPITAL ADMISSIONS FOR DENTISTRY

Boys aged between five and nine are being admitted to hospital because of problems with their teeth more than any other age group, figures show.

Statistics released by the Health and Social Care Information Centre (HSCIC) also show wide regional disparities for children in England, with the South Yorkshire region having more than nine times the rate of hospital admissions for dentistry among under 15 s compared with Leicestershire and Lincolnshire, which had the lowest overall.

Across all age groups, the figures show far more people are going to hospital for teeth or gum problems in the most deprived areas of the country, with more than a quarter - 28 per cent - coming from the 20 per cent most deprived areas nationally.

In response to the data, Professor Nigel Hunt, Dean, Faculty of Dental Surgery at the Royal College of Surgeons said: 'This data is a stark reminder of the inequalities in children's oral health that persist across the country. We are alarmed that the South Yorkshire region has over 9 times the rate of hospital admissions for dentistry among under fifteen year olds compared to Leicestershire and Lincolnshire.

'In addition 5-9 year olds continue to account for the highest age group to be admitted to hospital for tooth decay when this is nearly entirely preventable.

'Hospital treatment is often required for dental problems that are more serious and complex. We strongly urge the government to invest in further research to understand the variation.

'A national public health programme is urgently needed to tackle preventable tooth decay. 